\title{
BMJ Open Unmet need for primary healthcare and associated individual and household- level factors in Kenya: results from a national survey
}

\author{
Peter O Otieno (D , , ${ }^{1}$ Francis Kiroro, ${ }^{1}$ Cynthia Runyenje, ${ }^{1}$ Pauline Kamau ${ }^{2}$
}

To cite: Otieno PO, Kiroro F, Runyenje $\mathrm{C}$, et al. Unmet need for primary healthcare and associated individual and household-level factors in Kenya: results from a national survey. BMJ Open 2021;11:e041032. doi:10.1136/ bmjopen-2020-041032

- Prepublication history and supplemental material for this paper is available online. To view these files, please visit the journal online (http://dx.doi. org/10.1136/bmjopen-2020041032).

Received 31 May 2020 Revised 02 May 2021 Accepted 04 May 2021
Check for updates

(C) Author(s) (or their employer(s)) 2021. Re-use permitted under CC BY-NC. No commercial re-use. See rights and permissions. Published by BMJ.

${ }^{1}$ African Population and Health Research Center, Nairobi, Kenya ${ }^{2}$ Kenya National Bureau of Statistics, Nairobi, Kenya

Correspondence to

Peter 0 0tieno;

pootienoh@gmail.com

\section{ABSTRACT}

Objective To determine the prevalence of unmet need for primary healthcare and associated individual and household-level factors in Kenya.

Design The data for this study are drawn from the 2016 Kenya Integrated Household Budget Survey (KIHBS). A multistage sampling technique involving a systematic selection of clusters at the national level and final selection of households was used.

Setting This study was conducted in Kenya. The KIHBS is a nationally representative survey on a wide range of indicators to assess the progress made in improving the living standards of the population at the national level. Participants A total of 9447 households comprising 15539 household members who reported a sickness or injury over the 4 weeks preceding this survey were included in this study. The study respondents comprised of the household heads.

Primary outcome measure The primary outcome of this study is unmet need for primary healthcare defined as an unexpressed demand for primary healthcare following a reported sickness or injury over the 4 weeks preceding this survey.

Results About one in every five study participants experienced an unexpressed demand for primary care. The odds of having unmet need for primary healthcare were $68 \%$ higher among participants without health insurance coverage compared with those with health insurance (adjusted OR 1.68; $\mathrm{p}<0.001 ; 95 \% \mathrm{Cl} 1.34$ to 2.09 ) and $45 \%$ higher among households headed by single or unmarried persons compared with the those who were in a marital union (adjusted OR 1.45; $\mathrm{p}<0.05 ; 95 \% \mathrm{Cl} 1.06$ to 1.98 ).

Conclusions Our findings show that there is still a considerable unexpressed demand for primary care services despite widespread implementation of Universal Health Coverage (UHC) in Kenya, with households without a health insurance cover bearing the highest burden. Therefore, the design of UHC reforms in Kenya should focus on embedding social health protection to escalate the demand for primary healthcare services.

\section{INTRODUCTION}

Universal Health Coverage (UHC) is at the centre of current global efforts to strengthen health systems and improve accessibility and
Strengths and limitations of this study

- Our results provide crucial evidence that complements the assessment of universal healthcare in Kenya.

- This study provides useful insights for the planning and delivery of interventions that improve the demand for primary healthcare services.

- The study sample is representative of the entire population in Kenya hence the findings are generalisable.

- The measurement of unmet need for primary healthcare in this study is subjective and relies on perceived healthcare needs that do not translate into demand hence the possibility of recall bias cannot be overemphasised.

- The study focus on non-use of appropriate primary healthcare services rather than a dynamic perspective including a clinician-validated unmet need and suboptimal use of primary healthcare. However, the results provide essential evidence for more rigorous investigations of unmet for primary healthcare in Kenya and sub-Saharan Africa.

availability of health services to all, without risk of impoverishment or financial hardships. ${ }^{1}$ Thus, UHC is best considered in the context of whether the people in need of primary care receive it or not. ${ }^{2}$ The unmet need for healthcare, which is defined as an unexpressed demand for healthcare, accounts for the perceived healthcare needs that do not translate into demand. ${ }^{34}$ Until now, most estimates for the unmet need for primary healthcare have been studied in developed countries. ${ }^{3}{ }^{5-9}$ In particular, the unexpressed demand stems from healthcare gaps related to availability, accessibility and acceptability. ${ }^{10} 11$ These gaps pose potential risks related to delays in seeking appropriate care, increased severity of illness and reduced prognosis. ${ }^{9} 12$

In Kenya, UHC is an integral part of the government's efforts to attain the sustainable 
development goal of ensuring healthy lives and promoting well-being for all at all ages. ${ }^{13}$ Despite the wide implementation of UHC, it is unclear whether the programme has improved access to essential interventions and explicit unified progressive health benefits package. Previous studies have shown that the Kenyan healthcare system is highly inequitable. ${ }^{14-17}$ Furthermore, policies aimed at addressing the healthcare needs of the poor and the most vulnerable groups in Kenya have not been properly evaluated and the success or otherwise of the primary healthcare reforms have been inferred from narrowly focused data or anecdotal accounts. ${ }^{18} 19$

Information on unmet need for primary care services is critical for the provision of UHC. However, most studies on access to primary healthcare services in Kenya are based on the conventional need-adjusted healthcare utilisation model. ${ }^{16-22}$ In this study, we assessed the unmet need for primary healthcare services and associated individual and household-level factors in Kenya.

\section{METHODS}

\section{Study design and setting}

The data used in this study are drawn from the Kenya Integrated Household Budget Survey (KIHBS) conducted between 2015 and 2016. ${ }^{23}$ The KIHBS is a nationally representative survey on a wide range of indicators to assess the progress made in improving the living standards of the population at the national level. A multistage sampling technique involving a systematic selection of 2400 clusters at the national level and a final selection of 24000 households was used. Weighting was done based on the selection probabilities in each domain whereby the design weights were adjusted in accordance with survey response. ${ }^{23}$ Details of the design of KIHBS are available online (https://www.knbs.or.ke). In this study, a total of 9447 households comprising of 15539 household members who reported a sickness or injury over the 4 weeks preceding this survey were included.

\section{Data collection}

Interviewer-administered structured questionnaires were used to collect information on sociodemographic characteristics such as age, sex, household size, level of education and residence, healthcare utilisation and healthcare-seeking behaviour. Other questions included health insurance coverage and expenditures. The study respondents comprised of the household heads. The participants with missing data on the study variables were excluded.

\section{Measurements}

\section{Dependent variable}

The primary outcome of this study is unmet need for primary healthcare assessed using the following three key questions: (1) Was (NAME) sick or injured in the last 4 weeks? (2) Did (NAME) consult a health service provider on this sickness /injury in the last 4 weeks? and
(3) What kind of health facility did (NAME) visit? The study participants were coded as having unmet need for primary healthcare if they had an unexpressed demand for primary healthcare, that is, being sick or having an injury in the last 4 weeks and not consulting a health service provider or consulting unqualified healthcare service providers such as shops or kiosks, faith or traditional healers, etc. These set of questions have been previously validated as reliable in estimating the unmet for healthcare. ${ }^{24}$

\section{Independent variables}

We used Andersen's Health Behaviour Model (HBM) to conceptualise potential predictor variables. ${ }^{25}$ This model demonstrates the determinants of healthcare utilisation from a broad perspective. According to Andersen, the utilisation of healthcare services is influenced by the following three domains: need factors, enabling factors and predisposing factors. The need factors represent an individual's objective or subjective health status. Enabling factors refer to the available resources to facilitate access to healthcare services. Predisposing factors represent sociodemographic predictors of health service utilisation such as age, sex, level of education, ethnicity and religion. ${ }^{24}$ In this study, we adopted the following two categories of predictor variables based on the HBM: predisposing factors and enabling resources. The predisposing factors comprised age of the household head (ie, <30, 30-44, 45-59 and >60 years), sex (ie, male and female), marital status (ie, married or living with a partner, separated/ divorced/widowed or single/never married), household size (1-4 or $>5$ members) and educational level (ie, no formal education, primary, secondary and tertiary). Health insurance status, place of residence (urban vs rural) and economic activity status of the household head were included as enabling resources.

\section{Data analysis}

Frequencies, mean values, SDs and percentages were used to describe the background characteristics of the respondents with respect to the unmet need for healthcare. The Pearson $\chi^{2}$ test was used to describe the association between independent predictor variables and unmet need for healthcare. The multivariate logistic regression model was used to estimate the association of predictor variables with unmet need for primary healthcare. The strength of association was interpreted using the adjusted OR and $95 \%$ CI. The selection of the factors for the multivariable model was based on the variables conceptualised from the Andersen's HBM as more traditional level $\mathrm{p}$ values such as 0.05 used to select variables can fail in identifying variables known to be important. Survey design weights were incorporated in the model to improve the precision of survey estimates. ${ }^{26}$ The robust standard errors were computed based on the observed variability of the unmet need for primary healthcare among clusters hence correcting the CIs and $\mathrm{p}$ values for clustering. All 
statistical analyses were performed using Stata V.15 (Stata Corp, College Station, TX, USA).

\section{Ethical considerations}

The data used in this study were collected by the Kenya National Bureau of Statistics (KNBS), a public institution mandated to conduct surveys on behalf of the Kenyan government. ${ }^{23}$ It can be inferred from the study design of KIHBS and the actual data collection process that informed written consents were sought from all the study participants and identifying information were delinked from the analytical datasets. The data collection instrument used by the KNBS to collect the data used in this study has been provided as an online supplemental file 1.

\section{Patient and public involvement \\ No patient involved.}

\section{RESULTS}

\section{Background information}

Of the total 15539 household members, females constituted a higher proportion $(55 \%)$ compared with males $(45 \%)$. About half were children aged $<18$ years. Approximately $16 \%$ were aged between 30 and 44 years, $15 \%$ were aged between 18 and 29 years, $10 \%$ were aged between 45 and 59 years and $8 \%$ were aged $\geq 60$ years. A majority $(60 \%)$ had completed primary education. Most of the participants $(91 \%)$ lived in households headed by economically active household heads. Slightly more participants $(64 \%)$ resided in rural areas compared with urban (36\%). A higher proportion of participants (57\%) were from households with $\geq 5$ members compared with 1-4 members (43\%). Only $20 \%$ of the participants had a health insurance cover. Table 1 shows the background characteristics of the study participants.

\section{Unmet need for primary healthcare}

Table 2 shows the distribution of household members by the unmet need for primary healthcare. Of the total household members who reported a sickness or injury over the 4 weeks preceding this survey, $20 \%$ did not seek appropriate care. The unmet need for healthcare was slightly higher among households headed by females $(20 \%)$ compared with males $(19 \%)$ and among individuals living in households headed by individuals who were not economically active (22\%) compared with the unemployed $(20 \%)$. Household members without health insurance coverage had a higher unmet need for healthcare $(21 \%)$ compared with those with health insurance coverage $(13 \%)$. About $18 \%$ and $21 \%$ of the participants who were living in households headed by persons aged $\geq 60$ years and those headed by divorced, separated or widowed persons expressed the unmet need for primary care, respectively. Approximately $20 \%$ of those living in households with either 1-4 members or $\geq 5$ members expressed the unmet need for primary healthcare, respectively.

\begin{tabular}{|c|c|c|c|}
\hline $\begin{array}{l}\text { Characteristics } \\
\text { of the household } \\
\text { head }\end{array}$ & Category & Frequency & Percentage \\
\hline \multirow[t]{2}{*}{ Sex } & Male & 6977 & 44.90 \\
\hline & Female & 8562 & 55.10 \\
\hline \multirow[t]{5}{*}{ Age group (years) } & $<18$ & 7742 & 49.82 \\
\hline & $18-29$ & 2371 & 15.26 \\
\hline & $30-44$ & 2448 & 15.75 \\
\hline & $45-59$ & 1666 & 10.72 \\
\hline & $60+$ & 1312 & 8.44 \\
\hline \multirow[t]{3}{*}{ Marital status } & $\begin{array}{l}\text { Married/living } \\
\text { together }\end{array}$ & 5216 & 33.57 \\
\hline & $\begin{array}{l}\text { Divorced/ } \\
\text { separated/ } \\
\text { widowed }\end{array}$ & 1238 & 7.97 \\
\hline & Never married & 9085 & 58.47 \\
\hline \multirow{4}{*}{$\begin{array}{l}\text { Highest level of } \\
\text { education }\end{array}$} & No formal & 260 & 1.67 \\
\hline & Primary & 9388 & 60.42 \\
\hline & Secondary & 3881 & 24.98 \\
\hline & Tertiary & 2010 & 12.94 \\
\hline \multirow{2}{*}{$\begin{array}{l}\text { Engagement in } \\
\text { an economic } \\
\text { activity }\end{array}$} & No & 1350 & 8.69 \\
\hline & Yes & 14189 & 91.31 \\
\hline \multirow[t]{2}{*}{ Residence } & Rural & 9912 & 63.79 \\
\hline & Urban & 5627 & 36.21 \\
\hline \multirow[t]{2}{*}{ Household size } & $1-4$ & 6700 & 43.12 \\
\hline & $>5$ & 8839 & 56.88 \\
\hline \multirow{2}{*}{$\begin{array}{l}\text { Health insurance } \\
\text { coverage }\end{array}$} & Yes & 3061 & 19.70 \\
\hline & No & 12478 & 80.30 \\
\hline Total & & 15539 & 100.00 \\
\hline
\end{tabular}

\section{Regression of individual and household-level characteristics} and unmet need for primary healthcare

Table 3 shows the regression of individual and householdlevel characteristics. In the unadjusted model, the findings from this study revealed higher odds for unmet need for primary care among the participants living in households headed by divorced, separated or widowed persons compared with married persons (OR 1.29; $<<0.05 ; 95 \%$ CI 1.08 to 1.54$)$. Likewise, the likelihood of having an unmet need for healthcare was $37 \%$ higher among households headed by single or never married persons compared with those who were married or living together with their partners (OR 1.37; p<0.05; 95\% CI 1.00 to 1.86 ) and $83 \%$ higher among those without health insurance coverage (OR 1.83; $\mathrm{p}<0.001 ; 95 \%$ CI 1.47 to 2.28). In the adjusted model, the odds of having unmet need for primary care were $68 \%$ higher among participants without health insurance coverage (adjusted OR 1.68; p<0.001; 95\% CI 1.34 to 2.09 ) and $45 \%$ higher among households headed by single or unmarried persons (adjusted OR 1.45; $\mathrm{p}<0.05$; $95 \%$ CI 1.06 to 1.98 ). 
Table 2 Distribution of household members by unmet need for primary healthcare

\begin{tabular}{|c|c|c|}
\hline $\begin{array}{l}\text { Individual and household } \\
\text { characteristics }\end{array}$ & $\begin{array}{l}\% \text { Reported } \\
\text { unmet need } \\
\text { for primary } \\
\text { healthcare } \\
n=15539\end{array}$ & $P$ value \\
\hline Sex & & 0.373 \\
\hline Male & 19.4 & \\
\hline Female & 20.0 & \\
\hline Age group (years) & & 0.630 \\
\hline$<30$ & 18.9 & \\
\hline $30-44$ & 19.4 & \\
\hline $45-59$ & 20.0 & \\
\hline$>60$ & 20.0 & \\
\hline $\begin{array}{l}\text { Marital status of household } \\
\text { head }^{\star \star}\end{array}$ & & 0.001 \\
\hline Married & 19.0 & \\
\hline $\begin{array}{l}\text { Separated/divorced/ } \\
\text { widowed }\end{array}$ & 22.3 & \\
\hline Single/never married & 20.9 & \\
\hline Highest education level ${ }^{\star \star}$ & & 0.000 \\
\hline No formal & 25.0 & \\
\hline Primary & 21.0 & \\
\hline Secondary & 17.3 & \\
\hline Tertiary & 16.5 & \\
\hline $\begin{array}{l}\text { Engagement in an economic } \\
\text { activity }\end{array}$ & & 0.144 \\
\hline No & 21.7 & \\
\hline Yes & 19.5 & \\
\hline Household size & & 0.878 \\
\hline $1-4$ & 19.5 & \\
\hline$>5$ & 19.6 & \\
\hline Residence & & 0.478 \\
\hline Rural & 19.7 & \\
\hline Urban & 19.3 & \\
\hline Health insurance cover ${ }^{* *}$ & & 0.000 \\
\hline Yes & 13.2 & \\
\hline No & 21.1 & \\
\hline Total & 19.6 & \\
\hline
\end{tabular}

${ }^{*} \mathrm{p}<0.05 ;{ }^{* *} \mathrm{p}<0.001$

\section{DISCUSSIONS}

We examined the prevalence of unmet need for primary healthcare and associated factors in Kenya. About 20\% of the participants who reported a sickness or injury over the 4 weeks preceding this survey, did not seek appropriate care. This proportion is significantly higher compared with the $12 \%$ reported from the 2013 Kenya Household Expenditure Survey ${ }^{27}$ and almost double the prevalence of unmet need for primary healthcare reported from developed countries. ${ }^{28} 29$ The rise in the unexpressed demand for primary care over the past few years is unexpectedly high given that the Kenyan government has recently prioritised UHC as one of its agendas for socioeconomic transformation and consequently abolished user fees in public primary care facilities. ${ }^{15} \mathrm{~A}$ possible explanation for these results could be in part the poor integration of demand-driven frameworks through which optimal access to primary healthcare services can be achieved.

The finding of the multivariate analysis shows that odds of having an unmet need for primary healthcare were significantly higher among households headed by single or never married persons compared with those who were married or in a union. Consistent with our findings, substantial literature supports the positive association between marriage and the likelihood of appropriate healthcare utilisation. ${ }^{30-33}$ First being married may confer a strong social relationship that may result in appropriate health-seeking behaviour because spouses function as caretakers providing personal social capital that extends the need for appropriate healthcare. ${ }^{32}$ Second marriage has also been shown to create a division of labour and share responsibilities within the household resulting in the ability to dedicate one's effort, time and resource for appropriate healthcareseeking behaviour. ${ }^{31}$

This study also revealed that the odds of having an unmet need for primary care were significantly higher among household members without health insurance coverage. The finding corroborates the results of previous studies which have shown that having a health insurance cover improves access to primary healthcare by offering protection from unexpected out-of-pocket expenditures. ${ }^{3435}$ Despite the profound role of health insurance coverage in reducing the likelihood of unmet need for primary healthcare as shown in our study, only one in every five study participants had a health insurance cover. Previous studies have also revealed a low prevalence of health insurance in Kenya. ${ }^{23} 36$ In a context where more than three-quarters of the population is currently employed in the informal sector and more than half live below the national poverty line, attaining a high equitable health insurance coverage to bridge the gap on unmet need for primary healthcare may be problematic.

These findings ultimately offer two key lessons to policymakers in Kenya. First, the evidence presented in this study suggests that health insurance coverage is significantly associated with the unmet need for primary healthcare. Therefore, the policy options for bridging the gaps in the unmet need for primary healthcare should be modelled on health insurance coverage, as a form of social protection, to ensure sustainability. Second, the gaps in the demand for primary healthcare highlights the urgent need for policies that encourage better utilisation of primary healthcare services. This has been proposed as a channel of ensuring equilibrium in the demand and supply of healthcare services. 
Table 3 Factors associated with unmet need for primary healthcare

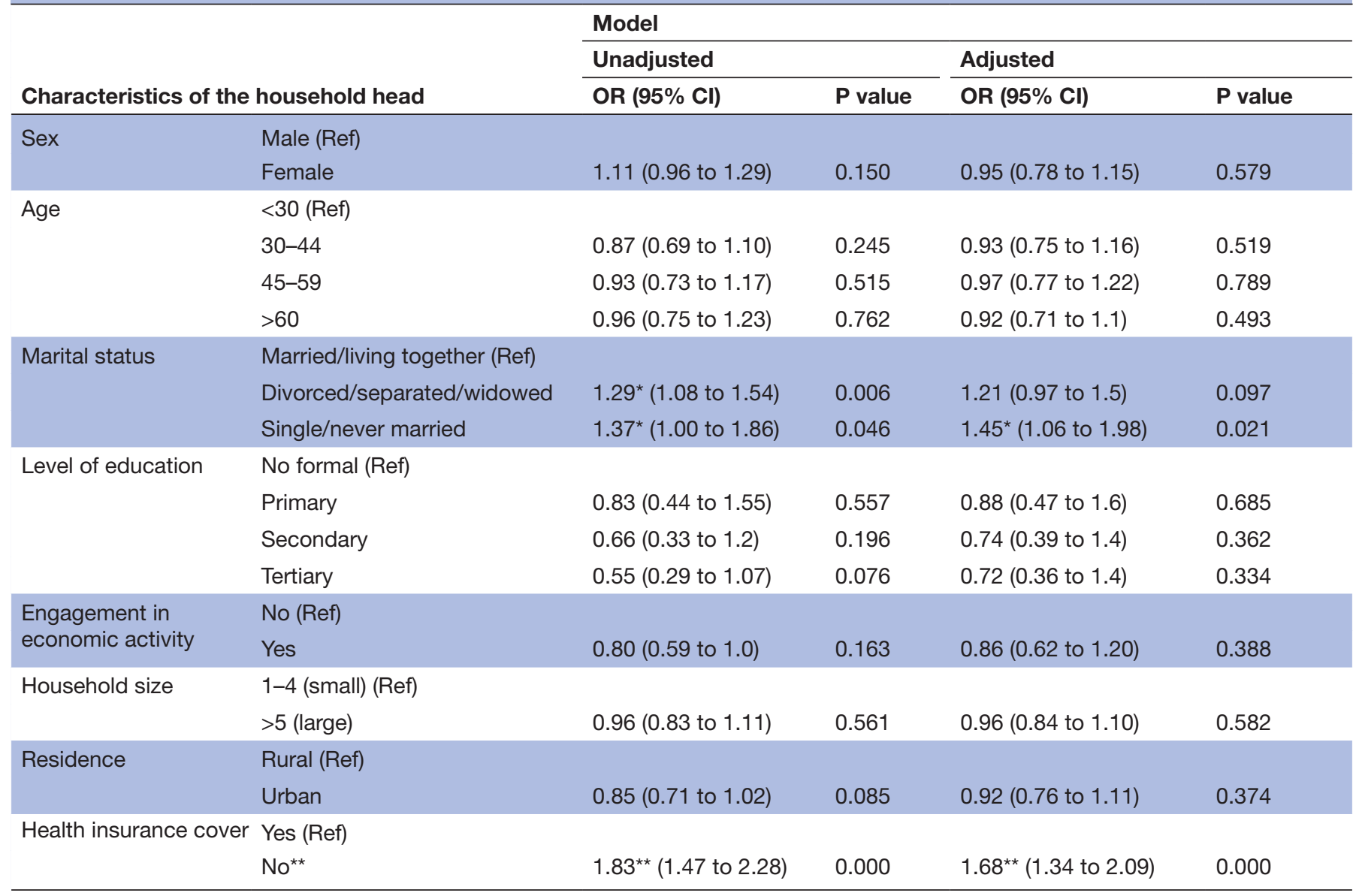

${ }^{*} \mathrm{p}<0.05 ;{ }^{* *} \mathrm{p}<0.001$.

\section{Strengths and limitations}

This study provides crucial evidence that complements the assessment of universal health coverage in Kenya and also provides useful insights for the planning and delivery of interventions that improve the demand for primary healthcare services. The study sample is representative of the entire population in Kenya hence the findings are generalisable.

This study has two major limitations. First, the measurement of unmet need for primary healthcare is subjective and relies on perceived healthcare needs that do not translate into demand hence the possibility of recall bias cannot be overemphasised. Second, the study focus on non-use of appropriate primary healthcare services rather than a dynamic perspective including a clinician-validated unmet need and suboptimal use of primary healthcare. Despite these limitations, our results provide essential evidence for more rigorous investigations of unmet for primary healthcare in Kenya and sub-Saharan Africa.

\section{CONCLUSIONS}

Despite sustained health policy efforts, our study findings show that Kenya still faces significant gaps in the demand for primary healthcare with one in every five persons forgoing essential primary healthcare services. Hence, addressing the gaps in the demand for primary care services may be an essential step towards improving healthcare access. Although the recent government efforts to roll-out out UHC is timely, households without a health insurance cover still exhibit the highest unmet need for primary healthcare. Therefore, the design of UHC reforms in Kenya, cascading down to counties, should focus on embedding social health protection among the most vulnerable groups to accelerate palpable demand for primary healthcare services.

Twitter Peter 0 0tieno @Peter_Otienoh and Francis Kiroro @FrancisKiroro

Contributors P00: conceptualised the study, reviewed literature and contributed to data analysis. FK, CR and PK: substantive contributions to the conceptualisation of the study, data analysis and reviewed the manuscript. All authors read and approved the final manuscript.

Funding The authors have not declared a specific grant for this research from any funding agency in the public, commercial or not-for-profit sectors.

Competing interests None declared.

Patient consent for publication Not required.

Ethics approval The data used in this study are from Kenya National Bureau of Statistics, a public institution mandated to conduct surveys on behalf of the Kenyan government. Most of the ethical issues that would, therefore, arise from data collected by the researcher do not arise in this case. 
Provenance and peer review Not commissioned; externally peer reviewed.

Data availability statement Data are available in a public, open access repository. No additional data are available.

Supplemental material This content has been supplied by the author(s). It has not been vetted by BMJ Publishing Group Limited (BMJ) and may not have been peer-reviewed. Any opinions or recommendations discussed are solely those of the author(s) and are not endorsed by BMJ. BMJ disclaims all liability and responsibility arising from any reliance placed on the content. Where the content includes any translated material, BMJ does not warrant the accuracy and reliability of the translations (including but not limited to local regulations, clinical guidelines, terminology, drug names and drug dosages), and is not responsible for any error and/or omissions arising from translation and adaptation or otherwise.

Open access This is an open access article distributed in accordance with the Creative Commons Attribution Non Commercial (CC BY-NC 4.0) license, which permits others to distribute, remix, adapt, build upon this work non-commercially, and license their derivative works on different terms, provided the original work is properly cited, appropriate credit is given, any changes made indicated, and the use is non-commercial. See: http://creativecommons.org/licenses/by-nc/4.0/.

\section{ORCID iD}

Peter 0 0tieno http://orcid.org/0000-0001-6828-8301

\section{REFERENCES}

1 WHO. Making fair choices on the path to universal health coverage: final report of the who consultative group on equity and universal health coverage, 2014.

2 Frenz P, Vega J. Universal health coverage with equity: what we know, don't know and need to know. In: Background paper for the global Symposium on health systems research, 2010.

3 Allin S, Grignon M, Le Grand J. Subjective unmet need and utilization of health care services in Canada: what are the equity implications? Soc Sci Med 2010;70:465-72.

4 Diamant AL, Hays RD, Morales LS, et al. Delays and unmet need for health care among adult primary care patients in a restructured urban public health system. Am J Public Health 2004;94:783-9.

5 Connolly S, Wren M-A. Unmet healthcare needs in Ireland: analysis using the EU-SILC survey. Health Policy 2017;121:434-41.

6 Hwang J. Understanding reasons for unmet health care needs in Korea: what are health policy implications? BMC Health Serv Res 2018;18:557.

$7 \mathrm{Ko} \mathrm{H}$. Unmet healthcare needs and health status: panel evidence from Korea. Health Policy 2016;120:646-53.

8 Pappa E, Kontodimopoulos N, Papadopoulos A, et al. Investigating unmet health needs in primary health care services in a representative sample of the Greek population. Int J Environ Res Public Health 2013;10:2017-27.

9 Ronksley PE, Sanmartin C, Quan H, et al. Association between perceived unmet health care needs and risk of adverse health outcomes among patients with chronic medical conditions. Open Med 2013;7:e21.

10 Smith S, Connolly S. Re-thinking unmet need for health care: introducing a dynamic perspective. Health Econ Policy Law 2020;15:440-57.

11 Zhen Z, Feng Q, Gu D. The impacts of unmet needs for long-term care on mortality among older adults in China. J Disabil Policy Stud 2015;25:243-51.

12 Long SK, King J, Coughlin TA. The implications of unmet need for future health care use: findings for a sample of disabled Medicaid beneficiaries in New York. INQUIRY 2005;42:413-20.

13 Okungu V, Chuma J, Mclntyre D. The cost of free health care for all Kenyans: assessing the financial sustainability of contributory and Non-contributory financing mechanisms. Int J Equity Health 2017;16:39.
14 Barasa E, Nguhiu P, Mclntyre D. Measuring progress towards sustainable development goal 3.8 on universal health coverage in Kenya. BMJ Glob Health 2018;3:e000904.

15 Barasa E, Rogo K, Mwaura N, et al. Kenya national Hospital insurance fund reforms: implications and lessons for universal health coverage. Health Syst Reform 2018;4:346-61.

16 Chuma J, Gilson L, Molyneux C. Treatment-Seeking behaviour, cost burdens and coping strategies among rural and urban households in coastal Kenya: an equity analysis. Trop Med Int Health 2007;12:673-86.

17 Chuma J, Maina T. Catastrophic health care spending and impoverishment in Kenya. BMC Health Serv Res 2012;12:413.

18 Chuma J, Okungu V. Viewing the Kenyan health system through an equity lens: implications for universal coverage. Int J Equity Health 2011;10:22.

19 McCollum R, Taegtmeyer M, Otiso L, et al. "Sometimes it is difficult for us to stand up and change this": an analysis of power within priority-setting for health following devolution in Kenya. BMC Health Serv Res 2018;18:906.

20 Anthonj C, Giovannini P, Kistemann T. Coping with ill-health: health care facility, chemist or medicinal plants? Health-seeking behaviour in a Kenyan wetland. BMC Int Health Hum Rights 2019;19:18.

21 Burton DC, Flannery B, Onyango B, et al. Healthcare-seeking behaviour for common infectious disease-related illnesses in rural Kenya: a community-based house-to-house survey. J Health Popul Nutr 2011;29:61.

22 Turin DR. Health care utilization in the Kenyan health system: challenges and opportunities. Inquiry 2010;2.

23 Kenya National Bureau of Statistics. Kenya integrated household budget survey (KIHBS) 2016 report, 2016. Available: https://www. knbs.or.ke/launch-201516-kenya-integrated-household-budgetsurvey-kihbs-reports-2/

24 Liberatos P, Elinson J, Schaffzin T, et al. Developing a measure of unmet health care needs for a pediatric population. Med Care 2000;38:19-34.

25 Andersen R, Newman JF. Societal and individual determinants of medical care utilization in the United States. Milbank $Q$ 2005;83:Online-only.

26 Lavallée P, Beaumont J-F. Why we should put some weight on weights. survey methods: insights from the field (SMIF), 2015.

$27 \mathrm{MOH}$. Kenya household health expenditure and utilisation survey. 2014. Nairobi: Government of Kenya, 2013.

28 Reeves A, McKee M, Stuckler D. The attack on universal health coverage in Europe: recession, austerity and unmet needs. Eur $J$ Public Health 2015;25:364-5.

29 Yoon YS, Jung B, Kim D, et al. Factors underlying unmet medical needs: a cross-sectional study. Int J Environ Res Public Health 2019;16:2391.

30 Simeonova E. Marriage, bereavement and mortality: the role of health care utilization. J Health Econ 2013;32:33-50.

31 Pandey KR, Yang F, Cagney KA, et al. The impact of marital status on health care utilization among Medicare beneficiaries. Medicine 2019;98:e14871.

32 Castevens C. The impact of family structure on spare capacity and health care utilization. Health Watch, 2014

33 Espinosa J, Evans WN. Heightened mortality after the death of a spouse: marriage protection or marriage selection? J Health Econ 2008;27:1326-42.

34 Otieno PO, Asiki G. Making Universal Health Coverage Effective in Low-and Middle-Income Countries: A Blueprint for Health Sector Reforms. In: Healthcare access-regional overviews. IntechOpen, 2020.

35 Spaan E, Mathijssen J, Tromp N, et al. The impact of health insurance in Africa and Asia: a systematic review. Bull World Health Organ 2012;90:685-92.

36 Otieno PO, Wambiya EOA, Mohamed SF, et al. Prevalence and factors associated with health insurance coverage in resource-poor urban settings in Nairobi, Kenya: a cross-sectional study. BMJ Open 2019;9:e031543. 